\title{
Linking forage choice behavior of goats with the metabolome of contrasting silages
}

\author{
R. Scherer, ${ }^{*}$ K. Gerlach, M. H. Ghaffari, and K.-H. Südekum† \\ Institute of Animal Science, University of Bonn, 53115 Bonn, Germany
}

\section{ABSTRACT}

The interrelationships between silage preference of ruminants and compounds that may affect forage choice are not yet fully enlightened. Analysis of the forage metabolome in addition to conventional chemical analysis and preference trials can provide new insights. Six silage treatments each of alfalfa $(\mathrm{AL})$ and red clover (RC), with different dry matter concentrations (222-391 $\mathrm{g} / \mathrm{kg}$ ), silage additives, and intended addition of soil, were produced in quadruplicate to obtain a range of qualities. After $120 \mathrm{~d}$ of ensiling, silages were sampled for chemical analysis, vacuum-packed, and refrigerated for subsequent preference trials with goats. Within 21 $\mathrm{d}$, each possible combination of 2 silages and an AL hay that served as control $(\mathrm{n}=21)$ was presented to goats (Saanen-type wethers, $\mathrm{n}=8$, body weight $105 \pm 2.7$ $\mathrm{kg}$ ) for $3 \mathrm{~h}$ for ad libitum intake. Comparisons among means for 3-h dry matter intake (DMI) for forages offered in choice situations were made using variance analysis, including terms for treatment and animal and the Waller-Duncan k-ratio $t$-test to separate means. The most preferred and avoided treatments of $\mathrm{AL}$ and RC silage amounted to $863,858,226$, and $282 \mathrm{~g} \mathrm{DMI} / 3$ $\mathrm{h}$, respectively. To further explore relations between silage composition and preference, a metabolome analysis of the most preferred and most avoided AL and $\mathrm{RC}$ treatments were conducted. Metabolites (all low molecular weight molecules) were analyzed by a nontargeted metabolite profiling in the range of $50-1,700$ Da. Metabolites showing the most distinct difference between preferred and avoided silages were identified by partial least squares discriminant analysis. In the 2 selected treatments of each plant species (those that were most different in forage preference), more than 6,400 compounds were detected and 2,010 were identified. Between preferred and avoided treatments, 934

Received April 1, 2020.

Accepted September 3, 2020.

*Current address: Kersia Deutschland GmbH, 53332 Bornheim, Germany.

†Corresponding author: ksue@itw.uni-bonn.de of the detected compounds differed in $\mathrm{RC}$ and 1,860 in $\mathrm{AL}$, of which 475 were altered in both plant species (251 were reduced and 186 were increased; only 38 behaved contrarily, meaning that they were increased in one substrate and decreased in the other). The database provides a useful foundation for the approach of explaining silage preference by ruminants.

Key words: goat, metabolome, preference, silage

\section{INTRODUCTION}

At the end of the 1990s, a trend was observed over the preceding 30 years that indicated that the proportion of forage conserved as silage had increased, whereas the proportion of haymaking had declined (Wilkinson et al., 1996). Since then, this development has continued (Martin et al., 2017). A comprehensive survey in the United States revealed that corn and alfalfa silages accounted for more than one-third of the dietary DM of dairy cows (Thoma et al., 2013). For many dairy feeding systems, silages provide the forage base because they supply energy, protein, and digestible fiber to ruminant diets (Martin et al., 2017). However, ensiled forage offered to ruminants has often resulted in a lower voluntary DMI compared with fresh (Donaldson and Edwards, 1976) or dried feed (Thiago et al., 1992). Various attempts have been made to establish relationships between silage composition and feed intake (e.g., Huhtanen et al., 2002, 2007) as well as feed preference, including volatile fatty acids, alcohols, acetone, $\mathrm{NH}_{3}$ N, ethyl esters (Gerlach et al., 2013, 2019; Brüning et al., 2018), and biogenic amines (Scherer et al., 2019). These studies are valuable for the exploration of the relationships between the variety of nutrients and sensory properties of silages and forage choice of ruminants. However, much is still unknown, and the specific mechanism or single compounds affecting intake or preference in many cases have not been elucidated (Grant and Ferraretto, 2018). Only recently, Guo et al. (2018) examined the metabolome of ensiled alfalfa (Medicago sativa L.) and detected 280 substances, of which 120 were identified. However, the focus of Guo et al. (2018) was on microbial community dynamics involved in en- 
siled alfalfa inoculated with lactic acid bacteria and not on the relationship between feed composition and feed choice or intake. Other than in silage research, metabolomics has been used for several years in food science research programs, such as Metabolomics for Plants, Health and OutReach, and it has the potential to address problem-solving approaches to global nutrition (Hall, 2007). In addition, the metabolome of a variety of foods and beverages such as vegetables and tea has already been characterized extensively (Ulrich et al., 2015; Xu et al., 2015).

This study aimed to make a snapshot of the metabolic status of 4 different silages with a known forage choice data to identify metabolites that may be related to a reluctant or improved silage preference. To achieve the most holistic view of relations between fermentation conditions, resulting silage composition, and feed choice behavior of goats, we, therefore, conducted a combination of comprehensive chemical analysis including analyses of fermentation acids and biogenic amines, $\mathrm{CP}$ fractionation, and forage preference trials (Scherer et al., 2019) with metabolomics. It is hypothesized that metabolomics can help to carve out links between forage and animals that are not detectable with the conventional chemical characterization of feedstuffs.

\section{MATERIALS AND METHODS}

\section{Silage Preparation and Sampling and Feed Choice Trial}

Silages were prepared from pure stands of alfalfa (AL, Medicago sativa L., first cut) and red clover (RC, Trifolium pratense L., first cut). Alfalfa was cultivated at the Educational and Research Center Frankenforst of the Faculty of Agriculture, University of Bonn (Königswinter, Germany). Red clover was cultivated at the Educational and Research Center Hofgut Neumühle, Münchweiler an der Alsenz, Germany. Both species were harvested at the late vegetative stage, and 6 silage treatments were prepared for each forage species. The treatments included untreated control silages with 2 different DM levels (low, 274 and 232, and high, 380 and $301 \mathrm{~g} / \mathrm{kg}$ for AL and RC, respectively), silage additives [biological additive based on homofermentative lactic acid bacteria (Lactobacillus plantarum; $3.0 \times 1,011$ colony-forming units/g; BIO); chemical silage additive $(2.5 \mathrm{~L} / \mathrm{t})$ based on sodium nitrite and hexamine (hexamethylenetetramine; CHE1); and chemical silage additive $(4 \mathrm{~L} / \mathrm{t})$ based on $75 \%$ formic acid buffered with sodium hydroxide to $\mathrm{pH} 2.5$ (CHE2)], and intended addition of soil to simulate a soil-contaminated substrate (SOIL, the addition of $7,600 \mathrm{~g}$ soil/t; for details see Scherer et al., 2019). The BIO and CHE1 treatments were prepared from the high DM levels and the CHE2 and SOIL treatments were prepared from the low DM levels. Refined sugar (sucrose; Diamant Zucker, Pfeifer \& Langen, Cologne, Germany) was added to AL and RC at ensiling to ensure adequate substrate availability. For this reason, $125 \mathrm{~g} / \mathrm{kg} \mathrm{DM}$ and $75 \mathrm{~g} / \mathrm{kg}$ DM sucrose were added to $\mathrm{AL}$ and $\mathrm{RC}$, respectively. The forage was processed in a clean dry place immediately after unloading from the loader wagon. For this purpose, the appropriate quantities were spread on a tarpaulin $(3 \times$ $4 \mathrm{~m}$ ) and treated accordingly. Afterward, each treatment was ensiled in quadruplicate in plastic barrels with a lid $(120 \mathrm{~L})$. Each barrel was sampled after 120 $\mathrm{d}$ of fermentation for analyses and then homogenized, vacuum-packed in 2 to $3 \mathrm{~kg}$ portions, and stored in a cooled chamber until feeding.

For a detailed description of the preparation of silages, the general and chemical analyses of fermentation variables, and the experimental procedure, see Scherer et al. (2019). Briefly, after predrying at $60^{\circ} \mathrm{C}$, the DM of the silages was estimated by oven-drying a triplicate subsample overnight at $105^{\circ} \mathrm{C}$. A correction of $\mathrm{DM}\left(\mathrm{DM}_{\mathrm{cor}}\right)$ for the loss of volatiles during drying was conducted using the following equation (Weißbach and Strubelt, 2008): $\mathrm{DM}_{\text {cor }}=\mathrm{DM}+(1.05-0.059 \times \mathrm{pH})$ $\times$ total VFA $(\mathrm{C} 2$ to $\mathrm{C} 6)+0.08 \times$ lactic acid $+0.77 \times$ 1,2 -propanediol $+0.87 \times 2,3$-butanediol $+1.00 \times$ total of other alcohols ( $\mathrm{C} 2$ to $\mathrm{C} 4)$. All concentrations are expressed as $\mathrm{g} / \mathrm{kg}$. Samples for all other analyses were freeze-dried in duplicate (P18K-E-6; Dieter Piatkowski, Munich, Germany) and then ground using 3- and finally 1 -mm screens.

Proximate analyses of the silage samples and of an AL hay that served as a control in both preference trials were performed according to VDLUFA (2012), and method numbers were given. Ash and crude lipids (CL) were analyzed using methods 8.1 and 5.1. Crude protein was determined by Dumas combustion (4.1.2, Elemental Analyzer rapid micro N cube, Elementar Analysensysteme GmbH, Langenselbold, Germany). The concentrations of NDF [6.5.1; assayed with heatstable amylase (aNDF)], ADF (6.5.2), and ADL (6.5.3) were analyzed using the Fiber Analyzer Ankom A2000 (Ankom Technology, Macedon, NY). The NDF and ADF values are expressed exclusive of residual ash (aNDFom, ADFom). In accordance with point 8.8 of method 6.5.2, the analysis of ADFom was performed sequentially for pectin-containing $\mathrm{AL}$ and RC samples.

The Hohenheim gas test (method 25.1; VDLUFA, 2012) was conducted to measure the 24 -h in vitro gas production (GP) and used to estimate the concentration of ME of the AL and RC silages using the following equation (GfE, 2017): $\mathrm{ME}$ (MJ/kg organic matter) = $12.49-0.0114 \times$ ADFom $+0.00425 \times \mathrm{CP}+0.0269 \times$ 
$\mathrm{CL}+0.01683 \times \mathrm{GP} ; \mathrm{ME}(\mathrm{MJ} / \mathrm{kg} \mathrm{DM})=\mathrm{ME}(\mathrm{MJ} / \mathrm{kg}$ organic matter $) \times[1,000-$ ash $] / 1,000$. Ash, CP, CL, and ADFom are in $\mathrm{g} / \mathrm{kg} \mathrm{DM}$, and GP is in $\mathrm{mL} / 200 \mathrm{mg}$ DM.

Frozen subsamples $(50.0 \mathrm{~g})$ of silages were used for the determination of lactic acid, acetic acid, $\mathrm{pH}$, ammonia-N, and water-soluble carbohydrates. Coldwater extracts were prepared by blending the frozen samples with a mixture of $300 \mathrm{~mL}$ of distilled water and $1 \mathrm{~mL}$ of toluol, kept in a refrigerator overnight, and afterward, filtered with a folded filter paper (MN 615, Macherey-Nagel, Düren, Germany). The $\mathrm{pH}$ in the extract was determined potentiometrically using a calibrated $\mathrm{pH}$ electrode. The extract was filtered through a Minisart syringe filter (pore size $0.45 \mu \mathrm{m}$; Sartorius, Göttingen, Germany) according to Weiß and Kaiser (1995). Volatile fatty acids and alcohols were determined by gas chromatography (flame ionization detector, Shimadzu Deutschland, Duisburg, Germany), as described by Weiß (2001). The analysis of propanol, methanol, 1-butanol, and 2-butanol was performed following Weiß and Sommer (2012). The lower detection limit for VFA and alcohol was $0.01 \%$, and for esters, it was $0.001 \%$. The $\mathrm{NH}_{3}-\mathrm{N}$ concentration was analyzed colorimetrically based on the Berthelot reaction, using a continuous flow analyzer (Skalar Analytical, Breda, Netherlands). The concentration of water-soluble carbohydrates was determined with the anthrone method according to von Lengerken and Zimmermann (1991).

For each forage species, one preference trial with Saanen-type wethers (German Improved White Goat breed, $\mathrm{n}=8$, body weight $105 \pm 2.7 \mathrm{~kg}$ ) was conducted to evaluate the feed choice behavior following the procedure of Burns et al. (2001). Animal care and experimental procedures were conducted according to the German Guidelines and Regulations on Animal Care (Deutsches Tierschutzgesetz). Two wethers shared an indoor pen of approximately $2 \times 3 \mathrm{~m}$ bedded with straw. Every morning, before offering the silages, the animals were tethered for the duration of experimental feeding, and it was ensured that they could drink and lie down. Crucial for collecting reliable preference data is the adaptation period before the experimental phase (Kyriazakis et al., 1990), where single meals of each AL and RC silage treatment and AL hay were offered once in randomized order to allow the animals to associate the forage with the smell, taste, and postingestive metabolic response. The AL hay was used as a standard in both runs so that quantitative comparisons between both runs were possible.

Within the $21 \mathrm{~d}$ of the following experimental period, each possible combination of 2 silages and the AL hay $(\mathrm{n}=21)$ was presented for $3 \mathrm{~h}$ for ad libitum intake to goats in randomized order. Each forage of the pair was offered in a separate plastic box $(400 \times 340 \times$ $250 \mathrm{~mm}$ ), and the forage pairs were presented side by side and were randomly allocated each day to prevent a habit reflex. Goats had free access to both feeding boxes so that free choice between the 2 forages could be guaranteed. The boxes were weighed $30 \mathrm{~min}$ after starting to feed (initial forage choice) and after $3 \mathrm{~h}$. To ensure ad libitum feed intake, the respective forage was refilled as soon as less than $300 \mathrm{~g}$ remained in the box. Each day, the experimental meal was offered for $3 \mathrm{~h}$, starting at $0730 \mathrm{~h}$.

To have the optimum comparison of feed composition with regard to preferred and avoided feed compounds, the most and least preferred silage treatment of each preference trial was selected for metabolome analysis. In both forage species, it was the untreated, high DM control $(\mathbf{C O N})$ and the soil-treated, low DM forage (SOIL). The abbreviations for the treatments, which are used in the following, are composed of the abbreviation for the forage species (AL or RC), the DM concentration $(38,30,27$, or $23 \%$ ), and CON or SOIL (i.e., AL38CON, RC30CON, AL27SOIL, and RC23SOIL). The chemical composition and preference (expressed as $\mathrm{g}$ DMI $/ 3 \mathrm{~h}$ for forages offered in choice situations) of the $\mathrm{AL}$ and $\mathrm{RC}$ silages selected for metabolome analysis are shown in Table 1.

\section{Sample Preparation and Processing}

Freeze-dried samples of the 4 silage treatments (n $=4$ per treatment) selected for metabolome analyses were homogenized, and $10 \mathrm{mg}$ filled in $2-\mathrm{mL}$ micro test tubes (Eppendorf Vertrieb Deutschland GmbH, Wesseling-Berzdorf, Germany) and forwarded to an external laboratory (Metabolomic Discoveries $\mathrm{GmbH}$, Potsdam, Germany). One milliliter methanol $\left(-20^{\circ} \mathrm{C}\right)$ including internal standards was added to $10 \mathrm{mg}$ of freeze-dried silage and immediately vortexed for $15 \mathrm{~s}$. For metabolite extraction, the tubes were incubated at $70^{\circ} \mathrm{C}$, with continuous shaking at $1,000 \mathrm{rpm}$ for $15 \mathrm{~min}$. Then $480 \mu \mathrm{L}$ of cold $\mathrm{H}_{2} \mathrm{O}$ was added. Samples were vortexed for $15 \mathrm{~s}$ and centrifuged at $13,500 \mathrm{rpm}$ for $15 \mathrm{~min}$. An aliquot of $200 \mu \mathrm{L}$ was taken and stored at $-80^{\circ} \mathrm{C}$ for further analyses.

\section{Nontargeted Metabolite Profiling}

For the metabolome analysis, the nontargeted profiling approach was chosen. Nontargeted metabolite profiling comprised analyses by gas chromatography-mass spectrometry (GC-MS) and liquid chromatographyquadrupole-time of flight-mass spectrometry (LC- 
The experimental design allowed statistical analysis of the preference trials by multidimensional scaling, as previously described by Burns et al. (2001) and Scherer et al. (2019) as well as by 2-factorial ANOVA after averaging the DMI of each forage offered in choice situations (averaged across each combination, $\mathrm{n}=6$ ). The ANOVA included terms for animals and forage. Within the forage treatments, the means were separated using the minimum significant difference from the WallerDuncan k-ratio $t$-test ( $\mathrm{k}=100$; Burns et al., 2001). Based on results from the ANOVA, the most and least preferred silage treatments $(\mathrm{n}=4$ with 4 replicates each) from both runs were selected for metabolome analysis.

The multivariate statistical analysis of the silage metabolite profiles was performed using a web tool MetaboAnalyst 4.0 (Chong et al., 2018; for detailed methodology see http://www.metaboanalyst.ca). Briefly, the metabolite data were log-transformed and Pareto scaled to correct for heteroscedasticity (variable variance) and the skewness of the data (van den Berg et al., 2006). A principal component analysis was conducted to illustrate the variances between the 4 different sample groups. The initial evaluation of the effect of single metabolites on feed choice was made calculating the metabolite ratio of the avoided to the preferred silage, i.e., AL27SOIL to AL38CON and RC23SOIL toRC30CON and ANOVA for comparison of those ratios. Compounds that differed (Bonferroni adjusted $P<0.01)$ in both forage species between avoided and preferred silages, in the same manner, were defined as choice-relevant metabolites which might influence feed selection. Metabolites showing ratios $>0$ may have a negative influence on forage choice and metabolites showing ratios $<0$ may have a positive influence on forage choice.

The variable selection was performed with a score of Variable Importance in Projection (VIP) from a partial least squares discriminant analysis (PLS-DA) using the plsr function provided by the $\mathrm{R}$ pls package (Mevik and Wehrens, 2007), to identify the differential metabolites between the groups and to rank them according to their importance in discriminating groups. Permutation tests were performed with PLS-DA models to validate the accuracy of the model. The classification and crossvalidation were performed using the corresponding wrapper function offered by the caret package (Kuhn, 2008).

Furthermore, correlations (Pearson coefficients) of the choice-relevant metabolites and preference (expressed as $\mathrm{g}$ of $\mathrm{DMI} / 3 \mathrm{~h}$ for forages offered in choice situations, $\mathrm{n}=16$ ) were calculated. All $P$-values from the correlations were corrected for multiple testing us- ing Benjamini and Hochberg (1995) false discovery rate (FDR, 1\%) adjustment by assuming n number of tests performed on the metabolites, and the $P$-values were sorted from lowest to highest. The following equation was used to calculate the FDR:

$$
F D R=\frac{n \times P(k)}{k},
$$

where $k=$ the individual relative test position; $P=$ $P$-values. Significance was declared at $P<0.05$, and a trend was denoted when $0.05 \leq P \leq 0.10$.

\section{RESULTS AND DISCUSSION}

\section{Descriptive Analysis}

For each forage crop, 6 different treatments were applied before ensiling to obtain a range of silage qualities prepared from the same sward. Although forage treatments generated only a few differences in fermentation acids and CP fractions, feed choice behavior of goats was strongly divergent (Table 1). In both forage species, the high DM CON silage was highly preferred with $748 \mathrm{~g}$ of $\mathrm{DM} / 3 \mathrm{~h}(\mathrm{AL} 38 \mathrm{CON})$ and $858 \mathrm{~g}$ of $\mathrm{DM} / 3 \mathrm{~h}$ (RC30CON). Wilting of forages to impair growth of undesired microorganisms in combination with providing sufficient fermentable substrate for lactic acid fermentation led to silages with high acceptance whereas low DM SOIL amounted to the lowest DMI with 226 $\mathrm{g}$ of DM/3 h (AL27SOIL) and $283 \mathrm{~g}$ of DM/3 h (RC23SOIL). According to our expectations, the intended addition of soil resulted in silages with the lowest preference. Contamination with soil during harvest increases the buffering capacity of the substrate such that its ensilability is reduced. Furthermore, it may increase the number of clostridial spores. Avoided silages contained the highest concentrations of acetic acid, which has been shown to reduce the DMI of ruminants before (Eisner et al., 2006). However, on the other hand, silages with the lowest acetic acid concentrations were not the most preferred treatments. Despite extensive chemical analysis (excluding the metabolomics approach), it was impossible to clearly assign differences in preference to the specific groups of compounds (Scherer et al., 2019). The contrasting forage choice behavior may, therefore, have had other causes.

Metabolome analysis of the 4 selected silage treatments revealed 6,403 metabolites in total, of which 1,860 differed between preferred and avoided AL treatments and 934 between the $2 \mathrm{RC}$ treatments. About $1,100(\mathrm{AL})$ and 500 metabolites (RC) were more con- 
centrated in the avoided compared with the preferred silages, and around $700(\mathrm{AL})$ and 400 metabolites (RC) were less concentrated in the avoided compared with the preferred silages. Of the total number of detected metabolites, 4,393 could not be annotated. We characterized the remaining 2,010 metabolites with HMDB, of which 334 metabolites could not be classified either because chemical taxonomic assignment failed or no unique hit in the database was found. Thus, we identified 1,678 metabolites by classifying them with their chemical taxonomy. The classification resulted in 16 superclasses, 68 classes, 162 subclasses, and 462 direct parents. The superclass of organic compounds represented $91 \%$ of all metabolites. According to the Encyclopedia Britannica (2009), organic compounds comprise any of a large class of chemical compounds in which one or more atoms of carbon are covalently linked to atoms of other elements, most commonly hydrogen, oxygen, or nitrogen. The highest shares of metabolites belonging to this superclass comprised peptides (40.2\% oligopeptides and $8.4 \%$ dipeptides) and amino acids (8.6\%). Table 2 shows relative shares of superclasses and classes each based on the entity of annotated metabolites $(\mathrm{n}=1,678)$.

Of the annotated metabolites $(\mathrm{n}=1,678), 68 \%$ contained nitrogen (Table 3). It was either pure nitrogen or in combination with one or 2 hydrogen atoms and one or 2 oxygen atoms. Partially, $\mathrm{N}, \mathrm{NH}$, and $\mathrm{NH}_{2}$ played a role as functional groups of biogenic amines. Of the annotated metabolites, $20 \%$ contained sulfur. For absolute and relative shares of $\mathrm{N}$ and $\mathrm{S}$ containing metabolites in the entity of annotated metabolites, see Table 3. Moreover, relative shares of $\mathrm{N}$ and $\mathrm{S}$ containing metabolites are shown in Table 3. A total of 1,044 metabolites contained aromatic compounds. Among them, 448 metabolites had one, 296 had 2, and 300 had 3 or more aromatic rings.

Despite not yet being able to annotate all metabolites, variances can be calculated via principal component analysis to depict variances in the sample sets. Our results revealed that principal component (PC) 1 clearly separated AL and RC (the substrate used for ensiling), explaining $40.7 \%$ of all variances; PC 2 separated the different silage treatments (AL38CON/RC30CON and AL27SOIL/RC23SOIL), explaining $22.9 \%$ of all variances in the data set.

\section{Effect of Single Metabolites on Forage Choice}

About 600 (AL) and 350 metabolites (RC), respectively, differed between the avoided and the preferred silages. In both plant species, approximately 200 metabolites were more concentrated, and 408 (AL) and 166 metabolites $(\mathrm{RC})$, respectively, were concentrated less in the avoided compared with the preferred silages. For both forage species, the same treatments (Scherer et al., 2019) were selected for metabolome analysis such that the metabolite ratios between both AL and RC silages could be compared. Statements about the possible relationships between metabolites and forage choice might thereby have higher validity than findings within 1 forage species. Compounds that differed in both forage species $(P<0.01)$ in the same manner were defined as choice-relevant metabolites. This definition applied to 160 of the 1,678 annotated metabolites. Very little information is available on metabolites in feedstuffs for ruminants and their effects on feed choice. Only major volatile organic compounds in silages have been studied in some detail, but for most of the numerous other products, the knowledge on their formation and mode of action in ruminants is limited (Gerlach et al., 2018). Of those metabolites that could be annotated and whose ratio of avoided to preferred silage was increased (AL27SOIL/AL38CON and RC23SOIL/RC$30 \mathrm{CON}$, respectively, $>0$ ), 66 metabolites overlapped in the $\mathrm{AL}$ and $\mathrm{RC}$ silages. Of those whose ratio of avoided to preferred silage was decreased (AL27SOIL/AL$38 \mathrm{CON}$ and RC23SOIL/RC30CON, respectively, $<0$ ), 94 annotated metabolites overlapped. All metabolites that were changed significantly (Bonferroni adjusted $P$ $<0.05)$ in both RC (RC23SOIL/RC30CON) and AL (AL27SOIL/AL38CON; ratio of each calculated comparison as $\log _{2}$-value $>0$ and $<0$, respectively) inclusive related superclasses, classes, subclasses, and direct parents are shown in Tables 4 and 5. Metabolites showing ratios $>0$ may have a negative influence on forage choice (Table 4), and metabolites showing ratios $<0$ may have a positive influence on forage choice (Table 5). Pearson correlation coefficients and $P$-values corrected for FDR between metabolites of choice-relevant compounds and the preference (expressed as g DMI/3 $\mathrm{h}$ for forages offered in choice situations) of goats of the $\mathrm{RC}$ and AL silage $(\mathrm{n}=16)$ are shown in Tables 4 and 5 . The majority of compounds that differed between preferred and avoided silage manifests a significant relation to preference, also after correction for FDR.

It has to be kept in mind that intake data from preference trials are not to be equated with DMI from production trials. Typically, differences in feed intake are much stronger when cows are having the possibility to choose between 2 or more feedstuffs (Keady and Murphy, 1998). Besides studying the metabolome of contrasting silages one objective of the study was to identify silage characteristics related to preference or avoidance. Because feeding behavior is more sensitive to feed characteristics in choice situations (Baumont, 1996), the design of the preference trial was chosen and judged as being appropriate for reaching these aims. 
Table 2. Relative shares of superclasses and classes each based on the entity of annotated metabolites $(\mathrm{n}=1,678)$ detected in alfalfa and red clover silages ( $\mathrm{n}=4$ with 4 replicates each)

\begin{tabular}{|c|c|c|c|}
\hline Superclass & $\begin{array}{c}\text { Share } \\
\text { (\% of all superclasses) }\end{array}$ & Class & $\begin{array}{c}\text { Share } \\
\text { (\% of all classes) }\end{array}$ \\
\hline \multirow[t]{12}{*}{ Organic compounds } & 17.14 & Organic acids and derivatives & 4.28 \\
\hline & & Benzenoids & 4.28 \\
\hline & & Organoheterocyclic compounds & 15.51 \\
\hline & & Naphthofurans & 0.53 \\
\hline & & Organic oxygen compounds & 1.60 \\
\hline & & Phenylpropanoids and polyketides & 9.10 \\
\hline & & Nucleosides, nucleotides, and analogs & 5.35 \\
\hline & & Alkaloids and derivatives & 1.60 \\
\hline & & Lignans, neolignans and related compounds & 2.14 \\
\hline & & Lipids and lipid-like molecules & 2.68 \\
\hline & & Organosulfur compounds & 3.21 \\
\hline & & Hydrocarbons & 1.07 \\
\hline \multirow[t]{6}{*}{ Organic acids and derivatives } & 8.57 & Carboxylic acids and derivatives & 1.07 \\
\hline & & Organic carbonic acids and derivatives & 0.53 \\
\hline & & Vinylogous acids & 0.53 \\
\hline & & Thiocarboxylic acids and derivatives & 0.53 \\
\hline & & Keto acids and derivatives & 0.53 \\
\hline & & Hydroxy acids and derivatives & 0.53 \\
\hline Organic oxygen compounds & 1.43 & Organooxygen compounds & 0.53 \\
\hline \multirow{3}{*}{ Organooxygen compounds } & 4.29 & Carbohydrates and carbohydrate conjugates & 1.07 \\
\hline & & Alcohols and polyols & 0.53 \\
\hline & & Carbonyl compounds & 2.67 \\
\hline \multirow[t]{16}{*}{ Organoheterocyclic compounds } & 22.86 & Pyridines and derivatives & 1.07 \\
\hline & & Quinolines and derivatives & 0.53 \\
\hline & & Dihydrofurans & 0.53 \\
\hline & & Pyrans & 0.53 \\
\hline & & Indoles and derivatives & 1.07 \\
\hline & & Piperidines & 0.53 \\
\hline & & Heteroaromatic compounds & 0.53 \\
\hline & & Benzopyrans & 1.07 \\
\hline & & Diazines & 1.07 \\
\hline & & Imidazopyrimidines & 0.53 \\
\hline & & Pteridines and derivatives & 0.53 \\
\hline & & Pyrrolidines & 0.53 \\
\hline & & Trithianes & 0.53 \\
\hline & & Benzoxazines & 0.53 \\
\hline & & Oxanes & 0.53 \\
\hline & & Benzothiazoles & 1.07 \\
\hline \multirow[t]{2}{*}{ Benzenoids } & 2.86 & Naphthalenes & 1.07 \\
\hline & & Benzene and substituted derivatives & 3.74 \\
\hline \multirow[t]{3}{*}{ Organic nitrogen compounds } & 4.29 & Organic nitrogen compounds & 1.07 \\
\hline & & Organonitrogen compounds & 1.07 \\
\hline & & Amines & 0.53 \\
\hline \multirow[t]{4}{*}{ Alkaloids and derivatives } & 5.71 & - & 0.53 \\
\hline & & Aporphines & 0.53 \\
\hline & & Tropane alkaloids & 0.53 \\
\hline & & Harmala alkaloids & 0.53 \\
\hline Nucleosides, nucleotides, and analogs & 1.43 & Purine nucleosides & 0.53 \\
\hline \multirow[t]{10}{*}{ Phenylpropanoids and polyketides } & 14.29 & Flavonoids & 0.53 \\
\hline & & Phenylpropanoic acids & 0.53 \\
\hline & & Isoflavonoids & 0.53 \\
\hline & & Cinnamic acids and derivatives & 1.60 \\
\hline & & Tannins & 0.53 \\
\hline & & 2-arylbenzofuran flavonoids & 0.53 \\
\hline & & Stilbenes & 0.53 \\
\hline & & Linear 1,3-diarylpropanoids & 0.53 \\
\hline & & Macrolides and analogs & 0.53 \\
\hline & & Neoflavonoids & 0.53 \\
\hline $\begin{array}{l}\text { Lignans, neolignans and related } \\
\text { compounds }\end{array}$ & 1.43 & Furanoid lignans & 0.53 \\
\hline Inorganic compounds & 1.43 & Homogeneous nonmetal compounds & 0.53 \\
\hline \multirow{4}{*}{ Lipids and lipid-like molecules } & 5.71 & Gycerolipids & 1.07 \\
\hline & & Prenol lipids & 2.67 \\
\hline & & Fatty acyls & 3.21 \\
\hline & & Lineolic acids and derivatives & 0.53 \\
\hline \multirow[t]{3}{*}{ Organosulfur compounds } & 4.29 & Organic disulfides & 0.53 \\
\hline & & Thioethers & 1.60 \\
\hline & & Isothiocyanates & 0.53 \\
\hline Hydrocarbons & 1.43 & Polycyclic hydrocarbons & 0.53 \\
\hline Organophosphorus compounds & 1.43 & Organic phosphoric acids and derivatives & 0.53 \\
\hline
\end{tabular}


Table 3. The number and relative shares of $\mathrm{N}$ and $\mathrm{S}$ containing metabolites in the entity of annotated metabolites $(\mathrm{n}=1,678)$ in alfalfa and red clover silages ${ }^{1}(\mathrm{n}=4$ with 4 replicates each) and relative shares of $\mathrm{N}$ and $\mathrm{S}$ containing metabolites each based on the totality of $\mathrm{N}(\mathrm{n}=$ $1,139)$ and $\mathrm{S}(\mathrm{n}=338)$ containing metabolites

\begin{tabular}{lccc}
\hline $\begin{array}{l}\text { Element/ } \\
\text { compound }\end{array}$ & $\begin{array}{c}\text { Number of all identified } \\
\text { metabolites }(\mathrm{n}=1,678)\end{array}$ & $\begin{array}{c}\text { Relative share (\%) of all } \\
\text { annotated metabolites }(\mathrm{n}=1,678)^{2}\end{array}$ & $\begin{array}{c}\text { Relative share }(\%) \text { of } \mathrm{N}- \\
(\mathrm{n}=1,139) \text { and } \mathrm{S}-(\mathrm{n}=338) \\
\text { containing metabolites }^{2}\end{array}$ \\
\hline $\mathrm{N}$ & 326 & 19.4 & 28.6 \\
$\mathrm{NH}$ & 660 & 39.4 & 57.9 \\
$\mathrm{NH}_{2}$ & 881 & 52.5 & 77.3 \\
$\mathrm{NO}$ & 2 & 0.1 & 0.2 \\
$\mathrm{NO}_{2}$ & 1 & 0.1 & 0.1 \\
$\mathrm{~S}$ & 167 & 10.0 & 49.4 \\
$\mathrm{SH}$ & 183 & 0.2 & 54.1 \\
$\mathrm{SO}$ & 3 & 0.2 & 0.9 \\
$\mathrm{SO}_{3}$ & 4 & 0.9 & 1.2 \\
$\mathrm{SO}_{4}$ & 15 & & 4.4 \\
\hline
\end{tabular}

${ }^{1}$ Silages were chosen as the most preferred (AL38CON and RC30CON) and the most avoided (AL27SOIL and RC23SOIL) silages from 2 preference trials with a total of 12 silage treatments (Scherer et al., 2019). AL = alfalfa silage; $\mathrm{RC}=$ red clover silage; CON $=$ untreated control; SOIL $=$ addition of $7,600 \mathrm{~g}$ of soil/ $\mathrm{t} ; 38,27,30$, and $23=\mathrm{DM}$ concentration $(\%)$ of treatment.

${ }^{2}$ The relative share of elements and compounds of the respective element (i.e., $\mathrm{N}, \mathrm{NH}, \mathrm{NH}_{2}, \mathrm{NO}, \mathrm{NO}_{2}, \mathrm{~S}, \mathrm{SH}, \mathrm{SO}, \mathrm{SO}_{3}$, and $\mathrm{SO}_{4}$ ) do not give $100 \%$ because several compounds containing $\mathrm{N}$ and S, respectively, can be part of a metabolite.

The metabolites we defined as choice-relevant compounds may have contributed to sensory characteristics of the silages or the postingestive feedback of the goats. Volatile compounds could have had the greatest effect on preference and avoidance of silage because they are probably the most flavorful compounds in silage and the first that is sensed (by smell or taste) when silage is offered to animals. Among other substances, they are composed of monoterpenes, sesquiterpenes, alcohols (monoterpene and sesquiterpene alcohols), ketones, phenols, aldehydes, coumarins, esters, and oxides (Parker, 2015), which were all found in the samples.

However, it has to be considered that sample preparation for metabolome analysis required freeze-drying and grinding of the silages, which can have caused the loss of volatile compounds. Their contribution to the overall profile might, therefore, be underestimated. Working on fresh, unground silage as an alternative would make it challenging to obtain a homogeneous representative sample, therefore, we decided to use freeze-dried, ground material, accepting that some volatiles might get lost.

The 66 metabolites being more concentrated in the avoided compared with the preferred silages could potentially have a negative effect on forage choice; most of them were negatively correlated (FDR-corrected $P$-values $<0.01)$ to preference expressed as short-time DMI for forages offered in choice situation. These metabolites consisted of oligopeptides (33), dipeptides (3), amino acids (6), lipids (fatty acyls, glycerolipids, and glycerophospholipids; 12), indolacetaldehyde, 1-pentenyl glucosinolate, styrene, methylfurane, xanthine, diadenosine tetraphosphate, L-carnitine, hydrocinnamic acid, ethyl 1-(ethylthio)ethyl disulfide, sphingosine, D-threitol, and erythritol.

Almost all sugars are decreased in the avoided compared with the preferred silages. The levels of glucose and fructose, 2 main sugars in plants, especially are very low in SOIL silages. Ruminants generally prefer feedstuffs with a sweet taste and avoid bitter substances (Provenza, 1995; Forbes, 2007). In goats, we have shown that the addition of sugar beets (containing considerable amounts of sucrose, fructose, glucose, and glycerol) to the ration strongly increased preference (Gerlach et al., 2017). Compounds that might positively contribute to sensory characteristics of silages were higher in the preferred silages: citric acid, malic acid (acidic, fruity), and glycerol with a sweet taste (HMDB, 2020), as well as volatile compounds such as ethyl butyrate that is known for a fruity and sweet odor, at least from a human perspective (Högnadóttir and Rouseff, 2003).

Contrary to suggestions of Weiß et al. (2016), ethyl esters showed no negative influence on forage choice, and ethyl butyrate even had a positive effect. Esters are known to be odorants, which is why they probably have an effect on the flavor of silage (Mo et al., 2001). According to Figueiredo et al. (2007), esters are the most abundant class of volatile compounds in RC silages, with ethyl esters being the predominant subclass of all esters. Ethyl acetate and ethyl lactate artificially added to forages did not affect the forage choice of goats (Gerlach et al., 2019) such that authors concluded that it is unlikely that ethyl esters as a single substance affect preference behavior of ruminants. Based on the current investigations, ethyl esters in combination with other compounds might also not be responsible for reduced silage acceptance. 
Scherer et al.: METABOLOMICS IN SILAGE AND FEED PREFERENCE FOR SILAGE EVALUATION

316

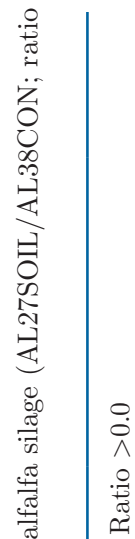

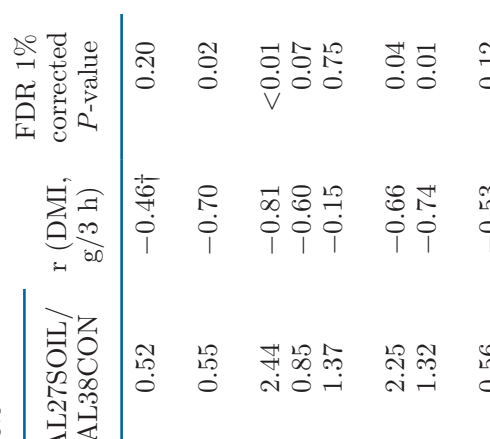

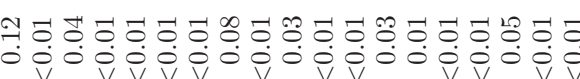

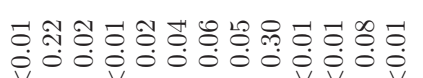

$\stackrel{\vec{\varphi}}{\dot{\varphi}}$

نี

ஜำ

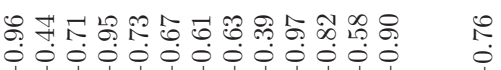

定

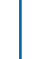

光号

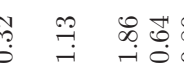

ำ

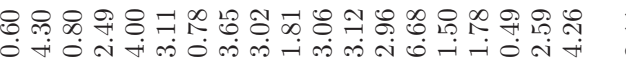

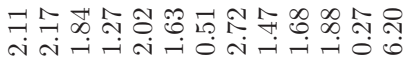

$\underset{\substack{\infty \\ \text { Si }}}{\infty}$

艉

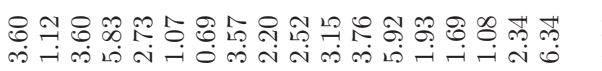

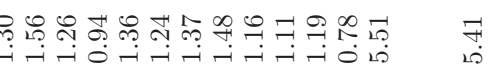

空

نำ
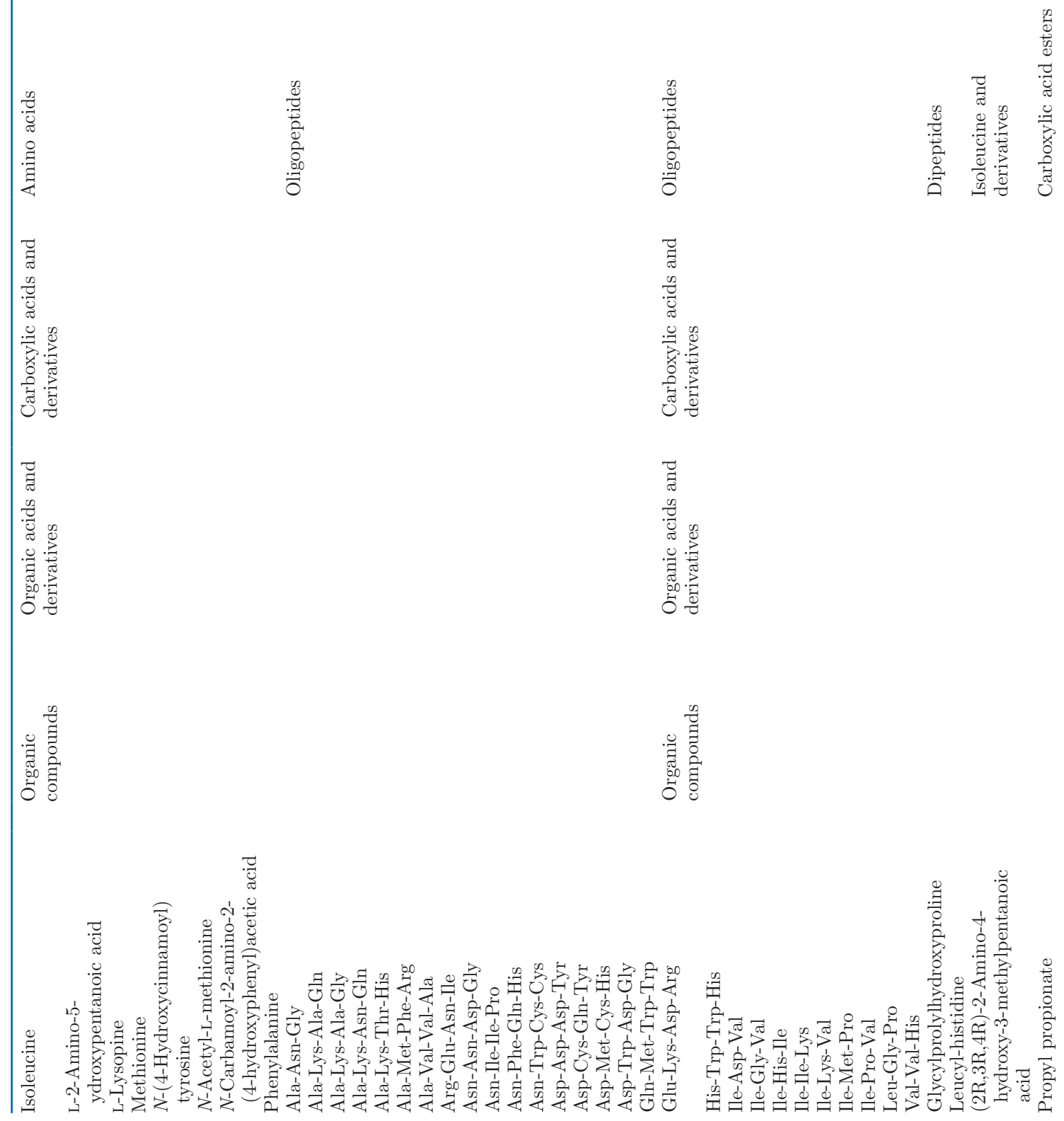
Scherer et al.: METABOLOMICS IN SILAGE AND FEED PREFERENCE FOR SILAGE EVALUATION

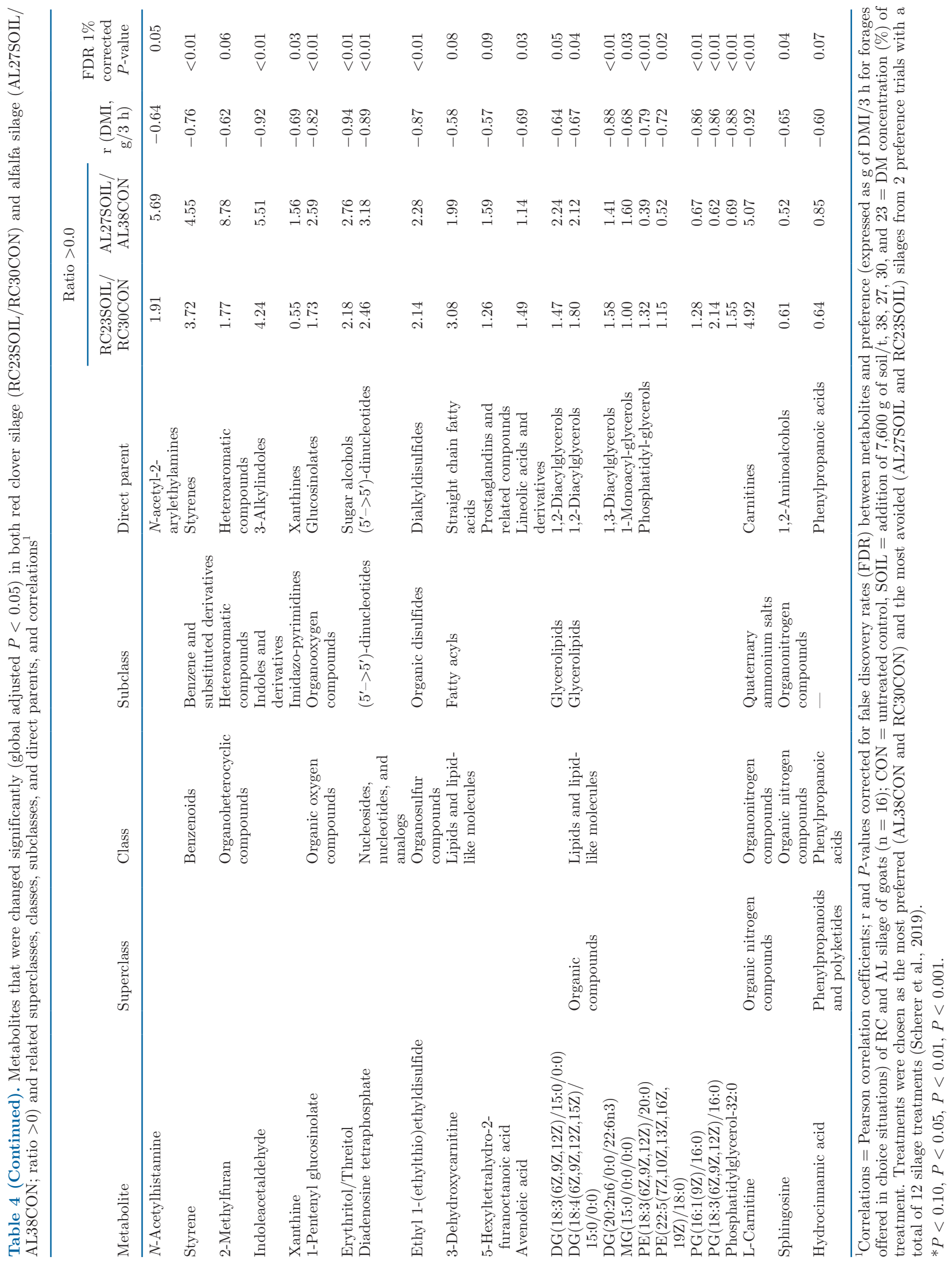


Scherer et al.: METABOLOMICS IN SILAGE AND FEED PREFERENCE FOR SILAGE EVALUATION

318

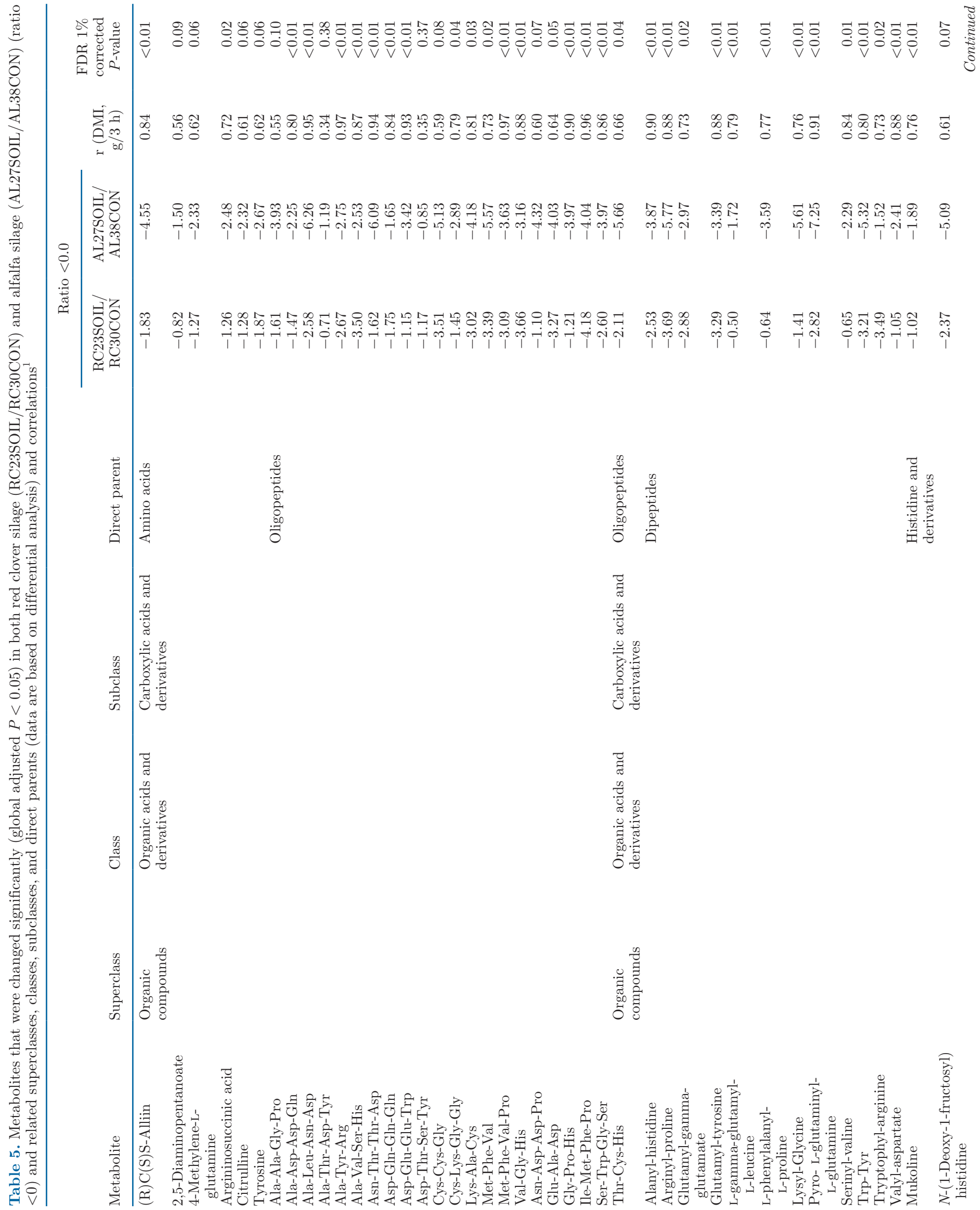


Scherer et al.: METABOLOMICS IN SILAGE AND FEED PREFERENCE FOR SILAGE EVALUATION

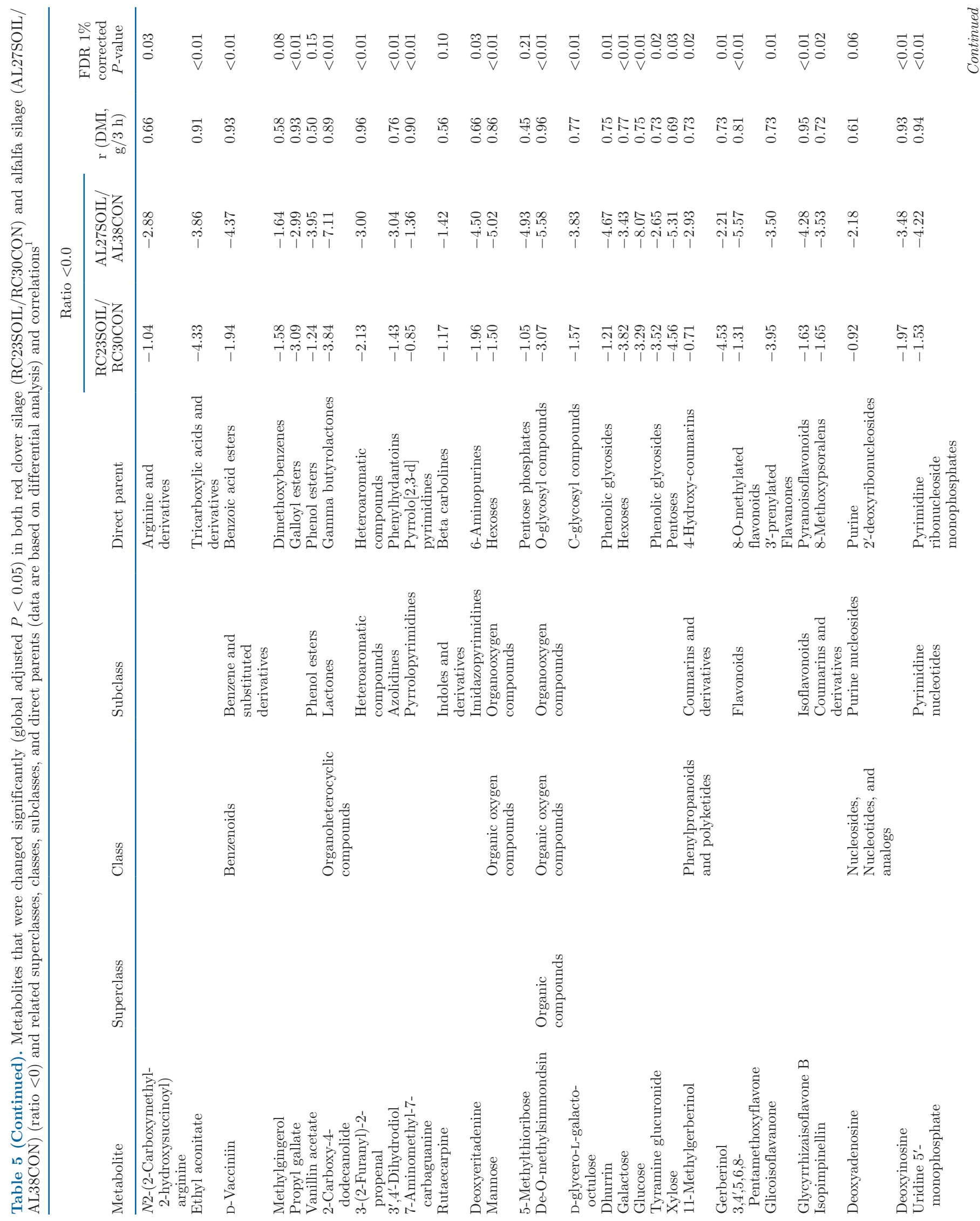


Scherer et al.: METABOLOMICS IN SILAGE AND FEED PREFERENCE FOR SILAGE EVALUATION

320

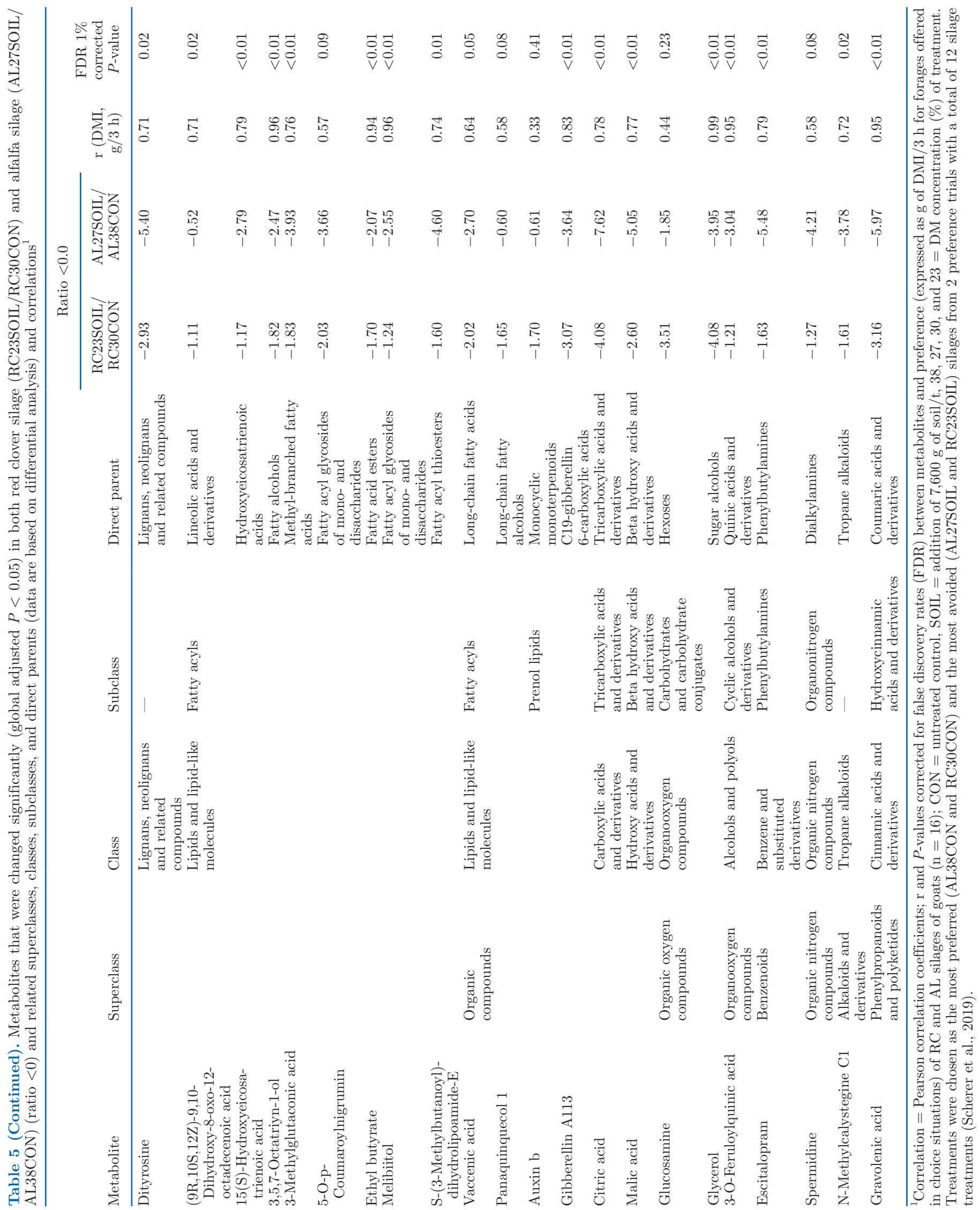




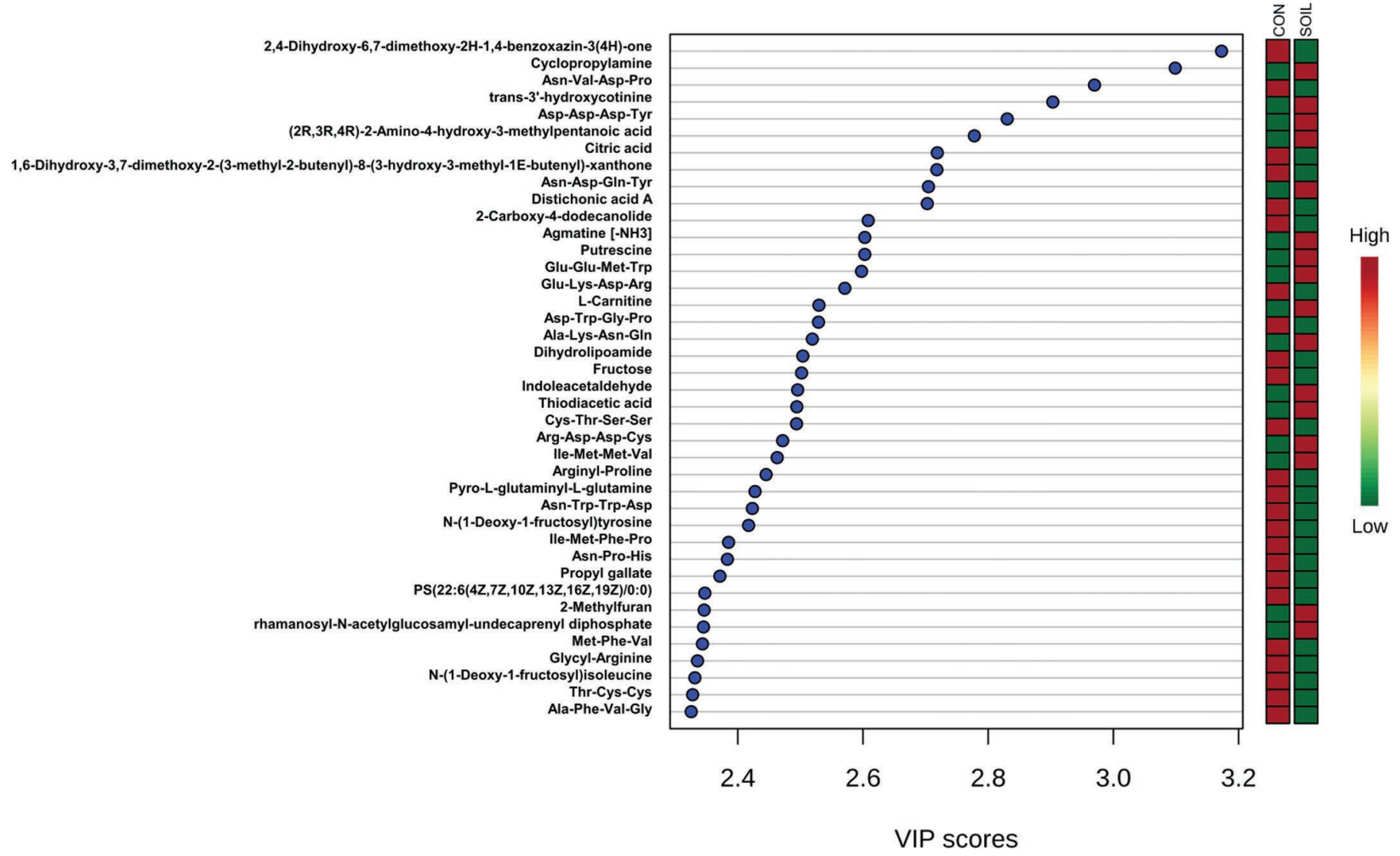

Figure 1. Important metabolites ranked by variable importance in projection (VIP) between the group based on the partial least squares discriminant analysis model. There are 29 metabolites that show a VIP score of $>2.4$. The colored boxes on the right indicate the relative concentrations of the corresponding metabolite in preferred (CON) versus avoided (SOIL) silages.

The 40 most important metabolites differing between CON and SOIL silages identified by PLS-DA are shown in Figure 1. A big share of them (15) belongs to oligopeptides, but there is no clear grouping of whether they are increased or decreased in avoided silages. Putrescine, the biogenic amine arising from decarboxylation of arginine, was higher concentrated in avoided silages. As reviewed by Scherer et al. (2015), the effect of ensiling conditions on its formation as well as its effect on DMI by ruminants has not yet been fully clarified. Putrescine administered in high concentrations of $100 \mathrm{~g} / \mathrm{d}$ to dairy cows influenced both milk yield and forage intake, and it was discussed that it might be a contributory factor, alone or combined with other amines, for the development of ketonemia (Lingaas and Tveit, 1992). Our data support the assumption that increased concentrations of putrescine in silages might also reduce forage preference. Carnitine is a quaternary ammonium salt, increased in avoided silages, accounts for a bitter taste, and acts as a taste modifying molecule (Behrens and Meyerhof, 2015). Also, thiodiacetic acid, known for its unpleasant odor (HMDB, 2020), and cyclopropylamine, described to have an ammoniacal to fish-like odor, were more concentrated in the avoided silages, but to the best of our knowledge, there has been no research on their effect on DMI or preference by ruminants yet. This list may provide approaches for further investigations on compounds in silages potentially influencing the forage choice or metabolism of ruminants. The effect of single substances identified in the present work on forage choice or DMI by ruminants should, therefore, be studied in future projects.

With the present study, we have demonstrated with a mainly descriptive approach how broad the chemical spectrum of the metabolites in silage immediately after opening the silos is and which classes of metabolites dominate. We consider this to be essential for a wellfounded overview of silage composition and the launch of a deeper exploration of feed-preference-relationships. However, although databases have been constructed (Johnson and Gonzalez, 2012), such as the HMDB (Wishart et al., 2013), identifying metabolites still represents a limiting step of metabolomics workflow; hence there is a need for progress that is currently going on. 


\section{CONCLUSIONS}

Preferred and avoided silages made from red clover and alfalfa differed in a huge number of metabolites identified by a nontargeted metabolomics approach. Some of the identified compounds offer the potential for being a preference-influencing compound through smell or taste, whereas others might affect the metabolism of ruminants. Therefore, the whole data set offers an important new approach to better understand the forage choice behavior of ruminants.

\section{ACKNOWLEDGMENTS}

This study was financially supported by the "Deutsche Forschungsgemeinschaft" (DFG, German Research Foundation, SU 124/31-1). The authors have not stated any conflicts of interest.

\section{REFERENCES}

Baumont, R. 1996. Palatability and feeding behaviour in ruminants. A review. Ann. Zootech. 45:385-400. https://doi.org/10.1051/ animres:19960501.

Behrens, M., and W. Meyerhof. 2015. Taste receptors. Pages 297-329 in Flavour Development, Analysis and Perception in Food and Beverages. J. K. Parker, J. S. Elmore, and L. Methven, ed. Woodhead Publishing, Cambridge, UK.

Benjamini, Y., and Y. Hochberg. 1995. Controlling the false discovery rate: A practical and powerful approach to multiple testing. J. R. Stat. Soc. Ser. B Methodol. 57:289-300. https://doi.org/10.1111/j .2517-6161.1995.tb02031.x.

Brüning, D., K. Gerlach, K. Weiß, and K.-H. Südekum. 2018. Effect of compaction, delayed sealing and aerobic exposure on forage choice and short-term intake of maize silage by goats. Grass Forage Sci. 73:392-405. https://doi.org/10.1111/gfs.12345.

Burns, J. C., D. S. Fisher, and H. F. Mayland. 2001. Preference by sheep and goats among hay of eight tall fescue cultivars. J. Anim. Sci. 79:213-224. https://doi.org/10.2527/2001.791213x.

Chong, J., O. Soufan, C. Li, I. Caraus, S. Li, G. Bourque, D. S. Wishart, and J. Xia. 2018. MetaboAnalyst 4.0: Towards more transparent and integrative metabolomics analysis. Nucleic Acids Res. 46(W1):W486-W494. https://doi.org/10.1093/nar/gky310.

Donaldson, E., and R. A. Edwards. 1976. Feeding value of silage: Silages made from freshly cut grass, wilted grass and formic acid treated wilted grass. J. Sci. Food Agric. 27:536-544. https://doi .org/10.1002/jsfa.2740270609.

Eisner, I., K.-H. Südekum, and S. Kirchhof. 2006. Beziehungen zwischen Fermentationscharakteristika von Silagen und der Futteraufnahme von Milchkühen (Relationships between silage fermentation characteristics and feed intake by dairy cows). Ubers. Tierernährg. $34: 197-221$.

Encyclopedia Britannica. 2009. Organic compound. Accessed on April 13, 2017. https://www.britannica.com/science/organic-compound.

Figueiredo, R., A. I. Rodrigues, and M. do Céu Costa. 2007. Volatile composition of red clover (Trifolium pratense L.) forages in Portugal: The influence of ripening stage and ensilage. Food Chem. 104:1445-1453. https://doi.org/10.1016/j.foodchem.2007.02.022.

Forbes, J. M. 2007. Voluntary Food Intake and Diet Selection in Farm Animals. 2nd. ed. CABI, Wallingford, UK.

Gerlach, K., E. Katsimeni, and K.-H. Südekum. 2018. Volatile organic compounds in silages - possible effects on intake and metabolism by ruminants and quality of ruminant products: A review. Pages 78-79 in Proceedings of the XVIII International Silage Conference, Bonn, Germany.
Gerlach, K., A. Reimink, U. Messerschmidt, and K.-H. Südekum. 2017. Ensiled sugar beets as dietary component and their effect on preference and dry matter intake by goats. Arch. Anim. Nutr. 71:297-310. https://doi.org/10.1080/1745039X.2017.1322795.

Gerlach, K., F. H. Ross, K. Weiß, W. Büscher, and K.-H. Südekum. 2013. Changes in maize silage fermentation products during aerobic deterioration and effects on dry matter intake by goats. Agric. Food Sci. 22:168-181. https://doi.org/10.23986/afsci.6739.

Gerlach, K., K. Weiß, and K.-H. Südekum. 2019. Effects of ethyl ester supplementation to forage on short-term dry matter intake and preference by goats. Arch. Anim. Nutr. 73:127-139. https://doi .org/10.1080/1745039X.2019.1575656.

GfE. 2017. Equations for predicting metabolisable energy and digestibility of organic matter in forage legumes for ruminants. Proc. Soc. Nutr. Physiol. 26:186-193.

Grant, R. J., and L. F. Ferraretto. 2018. Silage feeding management: Silage characteristics and dairy cow feeding behavior. J. Dairy Sci. 101:4111-4121. https://doi.org/10.3168/jds.2017-13729.

Guo, X. S., W. C. Ke, W. R. Ding, L. M. Ding, D. M. Xu, W. W. Wang, P. Zhang, and F. Y. Yang. 2018. Profiling of metabolome and bacterial community dynamics in ensiled Medicago sativa inoculated without or with Lactobacillus plantarum or Lactobacillus buchneri. Sci. Rep. 8:357. https://doi.org/10.1038/s41598-017 $-18348-0$.

Hall, R. D. 2007. Food metabolomics: META-PHOR: A new European research initiative. Agro Food Ind. Hi Tech 18:14-16.

HMDB. 2020. The Human Metabolome Database. Accessed Feb. 10 2020. http://www.hmdb.ca/metabolites.

Högnadóttir, A., and R. L. Rouseff. 2003. Identification of aroma active compounds in orange essence oil using gas chromatography-olfactometry and gas chromatography-mass spectrometry. J. Chromatogr. A 998:201-211. https://doi.org/10.1016/S0021 -9673(03)00524-7.

Huhtanen, P., H. Khalili, J. I. Nousiainen, M. Rinne, S. Jaakkola, T. Heikkilä, and J. Nousiainen. 2002. Prediction of the relative intake potential of grass silage by dairy cows. Livest. Prod. Sci. 73:111130. https://doi.org/10.1016/S0301-6226(01)00279-2.

Huhtanen, P., M. Rinne, and J. Nousiainen. 2007. Evaluation of the factors affecting silage intake of dairy cows: A revision of the relative silage dry-matter intake index. Animal 1:758-770. https://doi .org/10.1017/S175173110773673X.

Johnson, C. H., and F. J. Gonzalez. 2012. Challenges and opportunities of metabolomics. J. Cell. Physiol. 227:2975-2981. https://doi .org/10.1002/jcp.24002.

Keady, T. W. J., and J. J. Murphy. 1998. A note on the preferences for, and rate of intake of, grass silages by dairy cows. Ir. J. Agric. Food Res. 37:87-91.

Kuhn, M. 2008. Building predictive models in R using the caret package. J. Stat. Softw. 28. https://doi.org/10.18637/jss.v028.i05.

Kyriazakis, I., G. C. Emmans, and C. T. Whittemore. 1990. Diet selection in pigs: Choices made by growing pigs given foods of different protein concentrations. Anim. Sci. 51:189-199. https://doi.org/10 $.1017 /$ S0003356100005298.

Lingaas, F., and B. Tveit. 1992. Etiology of acetonemia in Norwegian cattle. 2. Effect of butyric acid, valeric acid, and putrescine. J. Dairy Sci. 75:2433-2439. https://doi.org/10.3168/jds.S0022 -0302(92)78004-7.

Lisec, J., N. Schauer, J. Kopka, L. Willmitzer, and A. R. Fernie. 2006. Gas chromatography mass spectrometry-based metabolite profiling in plants. Nat. Protoc. 1:387-396. https://doi.org/10.1038/ nprot.2006.59.

Martin, N. P., M. P. Russelle, J. M. Powell, C. J. Sniffen, S. I. Smith, J. M. Tricarico, and R. J. Grant. 2017. Invited review: Sustainable forage and grain crop production for the US dairy industry. J. Dairy Sci. 100:9479-9494. https://doi.org/10.3168/jds.2017-13080.

Mevik, B. H., and R. Wehrens. 2007. The pls package: Principal component and partial least squares regression in R. J. Stat. Softw. 18:1-23. https://doi.org/10.18637/jss.v018.i02.

Mo, M., I. Selmer-Olsen, A. T. Randby, S. E. Aakre, and A. Asmyhr. 2001. Fermentation products in grass silage and their effects on 
feed intake and milk taste. Pages 98-99 in Proc. 10th Int. Symp. Forage Conservation. Brno, Czech Republic.

Parker, J. K. 2015. Introduction to aroma compounds in foods. Pages 3-30 in Flavour Development, Analysis and Perception in Food and Beverages. J. K. Parker, J. S. Elmore, and L. Methven, ed. Woodhead Publishing, Cambridge, UK.

Provenza, F. D. 1995. Postingestive feedback as an elementary determinant of food preference and intake in ruminants. J. Range Manage. 48:2-17. https://doi.org/10.2307/4002498.

Scherer, R., K. Gerlach, and K.-H. Südekum. 2015. Biogenic amines and gamma-amino butyric acid in silages: Formation, occurrence and influence on dry matter intake and ruminant production. Anim. Feed Sci. Technol. 210:1-16. https://doi.org/10.1016/j .anifeedsci.2015.10.001

Scherer, R., K. Gerlach, J. Taubert, S. Adolph, K. Weiß, and K.-H. Südekum. 2019. Effect of forage species and ensiling conditions on silage composition and quality and the feed choice behaviour of goats. Grass Forage Sci. 74:297-313. https://doi.org/10.1111/ gfs.12414.

Thiago, L. R., M. Gill, and M. S. Dhanoa. 1992. Studies of method of conserving grass herbage and frequency of feeding in cattle. 1. Voluntary feed intake, digestion and rate of passage. Br. J. Nutr. 67:305-318. https://doi.org/10.1079/BJN19920037.

Thoma, G., J. Popp, D. Shonnard, D. Nutter, M. Matlock, R. Ulrich, W. Kellogg, D. S. Kim, Z. Heiderman, N. Kemper, F. Adom, and C. East. 2013. Regional analysis of greenhouse gas emissions from USA dairy farms: A cradle to farm-gate assessment of the American dairy industry circa 2008. Int. Dairy J. 31:S29-S40. https:// doi.org/10.1016/j.idairyj.2012.09.010.

Ulrich, D., T. Nothnagel, and H. Schulz. 2015. Influence of cultivar and harvest year on the volatile profiles of leaves and roots of carrots (Daucus carota spp. sativus Hoffm.). J. Agric. Food Chem. 63:3348-3356. https://doi.org/10.1021/acs.jafc.5b00704.

van den Berg, R. A., H. C. J. Hoefsloot, J. A. Westerhuis, A. K. Smilde, and M. J. van der Werf. 2006. Centering, scaling, and transformations: Improving the biological information content of metabolomics data. BMC Genomics 7:142. https://doi.org/10 .1186/1471-2164-7-142.

VDLUFA. 2012. Methodenbuch, Vol. III. Die Chemische Untersuchung von Futtermitteln. VDLUFA-Verlag, Darmstadt, Germany (in German). von Lengerken, J., and K. Zimmermann. 1991. Handbuch Futtermittelprüfung. Deutscher Landwirtschaftsverlag, Berlin, Germany (in German).

Weiß, K. 2001. Gärungsverlauf und Gärqualität von Silagen aus nitratarmen Grünfutter. Doctoral Thesis, Faculty of Agricultural and Horticultural Science, Humboldt-Universität zu Berlin, Germany (in German)

Weiß, K., and E. Kaiser. 1995. Milchsäurebestimmung in Silageextrakten mit Hilfe der HPLC. Wirtschaftseig. Futter. 41:69-80. (in German).

Weiß, K., B. Kroschewski, and H. Auerbach. 2016. Effects of air exposure, temperature and additives on fermentation characteristics, yeast count, aerobic stability and volatile organic compounds in corn silage. J. Dairy Sci. 99:8053-8069. https://doi.org/10.3168/ jds.2015-10323.

Weiß, K., and G. Sommer. 2012. Bestimmung von Estern und anderen flüchtigen organischen Substanzen (VOC) in Silageextrakten mit Hilfe der Gaschromatographie. VDLUFA-Schriftenr. 68:561-569. (in German).

Weißbach, F., and C. Strubelt. 2008. Correcting the dry matter content of grass silages as a substrate for biogas production. Landtechnik 63:210-211.

Wilkinson, J. M., F. Wadephul, and J. Hill. 1996. Silage in Europe-A Survey of 33 Countries. Chalcombe Publications, Ort, Bucks, UK

Wishart, D. S., T. Jewison, A. C. Guo, M. Wilson, C. Knox, Y. Liu, Y. Djoumbou, R. Mandal, F. Aziat, E. Dong, S. Bouatra, I. Sinelnikov, D. Arndt, J. Xia, P. Liu, F. Yallou, T. Bjorndahl, R. Perez-Pineiro, R. Eisner, F. Allen, V. Neveu, R. Greiner, and A. Scalbert. 2013. HMDB 3.0 - The Human Metabolome Database in 2013. Nucleic Acids Res. 41(D1):D801-D807. https://doi.org/10 $.1093 / \mathrm{nar} / \mathrm{gks} 1065$

Xu, J., F.-L. Hu, W. Wang, X.-C. Wan, and G.-H. Bao. 2015. Investigation on biochemical compositional changes during the microbial fermentation process of Fu brick tea by LC-MS based metabolomics. Food Chem. 186:176-184. https://doi.org/10.1016/j .foodchem.2014.12.045. 